Tunicata inter se, or otherwise to be the larval conditions of higher forms. My own observations, lowever, recorded in the ast July number of the "Quarterly Journal of Microscopical Science," have led me to believe that they are the free swim. ming reproductive Zooids of higher Tunicates, bearing the same relation to them as many free swimming Meduse do to some stationary hydroid colony. At the greater depth of 600 and 800 fathoms, various species of Terebratule were taken as representative of the class Brachiopoda.

Ascending yet higher to the subkingdom of the Mollusca, a large variety of interesting species rewarded our researches. Included among these were-Fusis contrarius, a common fossil of the Norfolk crag recently discovered in the living state in Vigo Bay by Mr. M'Andrew, and dredged by us in the same locality; also a species of Cassis, remarkable from its being more closely allied to $C$. Sabutron and other species inhabiting the Japanese and Chinese seas than to any of its Mediterranean or Atlantic congeners, This circumstance of lits affinity is the more remarkable when associated with the occurrence of a species of Hyalonema ( . lusitanica) off the samecoast, likewise scarcely distinguishable from the more familiar Japanese form H. Sieboldi.

The Annelida and Crustacea have also furnished a fair quota of new and interesting species, to be reverted to hereafter; and neither taking a step further onwards to the higher vertebrate sub-kingdom has good fortune entirely deserted us Availing ourselves, through the kind assistance of Prof. du Bocage, of the aid of the native fishermen and their appliances, we secured examples of several rare species of the deep-sea ground-sharks frequenting the Portugiese coast line; and among others a fine specimen of Pseudotriakis microdon, a species recently discovered and described by Prof. du Bocage and his gifted collaborateur, Felix de Brito Capello.

Generalising from the whole amount of material collected during our cruise off the Iberian coast, our plunder may be separated into two very distinct groups. One of these, includ. ing that collected from the shore line down to a depth of roo fathoms, presenting an interblending of Mediterranean species with those prevalent on our own more temperate coasts. Among these former I may more especially mention the occurrence of Dendrophyllia ramea, a well-known Mediterranean branching coral in great luxuriance at the mouth of the river Sado, this being, I think, the first record of this coral being taken so far north, and also from the same locality Calappa granulata, MTaia verrucosa, Murex trunculus and bran. daris, Cestum veneris, Veritillum cynomorian, and numerous other species belonging to the various Invertebrate divisions usually regarded as confined to the same more southern area. The residue and far smaller assemblage of species embraces those derived from the abyssal depths of fromi 400 to 800 fathoms, and all these, incliding many forms new to science, are characterised by their boreal or cold area facies, and in this respect contribute further evidence in support of the deductions arrived a by Dr. Carpenter, from his own more extended researches into the fauna of these same great depths in connection with the important expeditions of the Porcupinze and Lightning, and with which his name and those of his indefatigable colleagues, Prof Wyville Thomson and Mr. Gwyn Jeffreys, are so worthily con. nected.

In conclusion, it is my sincere hope that the rich reward at. tending our own humble efforts may stimulate other yacht owners to follow the example of my esteemed friend, Mr. Mar* shall Hall, influencing them likewise to devote their craft for one or a portion of a season to the cause of science, and to the exploration of those new deep-sea fields of discovery, now waiting to yield up the richest treasures to each eamest worker. Such men will find themselves more than compensated for the sacrifice of time or other interests by the fascinating nature of the work they undertake, in addition to earning for themselves the lasting gratitude of the scientific world.

Our well-appointed and expensively-fitted-out. Goveriment expeditions should explore the remoter depths; but British pluck and private enterprise should esteem it their especial privilege to unfold to us the yet hidden mysteries of the ocean world nearer home; and if, again, all shall not succeed in discovering new phases of animal life, there is much and even more important work to be effected in ascertaining accurately the bathye metrical range and geographical limits and distribution of those forms already known to us.

W. SAVille KENT

\section{PROF. BASTIAN ON THE GERM THEORY*}

FPIDEMIC and acute diseases have many characters in com. mon ; they constitute a family the members of which are united by a certain bond of unity, though at the same time they are in other respects strikingly different from one another. The "general" character of the symptoms originally gave rise to the notion that these affections were in the main dependent upon changes in the nature and quality of the blood. This view is still the one most commonly entertained, and which seems most likely to be true. And seeing that particular sets of symptoms recur with as much definiteness as individual differences of constitution will permit, we have a right to believe that the changes in the blood-however induced and of whatsoever nature they may be-mare definite and peculiar for each of these diseases. The successive changes in the blood which are the immediate causes of the phenomena of small-pox, must be quite different from those giving rise to the morbid state known as typhoid-fever. Variable as these several groups of symptoms are amongst themselves in individual cases, yet is there a general resemblance which suffices to maintain the distinctive nature of each affection. In this broad sense they are undoubtedly entitled to rank as "specific" diseases. They may be presumed to be associated with definite changes in the blood, though we have not a right to infer that such changes of state can only be induced in one way. Many well-known chemical changes are capable of being brought about by more than one agrency. And just as there is the best reason for believing that cancer or tubercle may be initiated $d e$ novo by the operation of irritants upon the tissues of certain individuals, and that such growths may subsequently be multiplied within the body by the contact-influence exerted by some of their disseminated particles; so may we suppose, not only that specific substances (contagia) may be capable of initiating specific changes in the blood, but that certain combinations of circum. stances may by their action upon the human body entail similar definite changes and states of blood. Having to do with a perverted nutritive activity and mode of growth in a limited area of tissue, cancer or tubercle may make their appearance; whilst, having an altered nutritive activity and set of changes occurring in the blood, this all-pervading tissue may lapse into the successive states peculiar to one or other of the specific diseases, and so give rise to the symptoms by which they are characterised. This is by no means a forced analogy. Can cancer or tubercle arise in the individual without any pre-existing " hereditary taint"? Can the states of blood peculiar to the several specific diseases arise $d c n o v o$, or independently of contagion? These are questions whose import is really similar. $\downarrow$

One of the great and distinguishing peculiarities of these specific diseases is their "contagiousness." Although very differently marked in the several affections, this property is as interesting as it is important. The fact of its existence seems always to have had a large share in determining the nature of the general views which have been held concerning these affections. Even in remote periods, by Hippocrates and others, they were commonly compared to processes of fermentation; whilst since the time of Linnæus, more especially, attention has been aften prominently directed to the many apparent similarities existing between the commencernent and spread of epidemic diseases, and the "flight, settlement, and propagation of the in sect-swarms which inflict blight upon vegetable life." + These

* Extracts from Introductory Lecture on Epidemic and Specific Contagious Diseases : Considerations as to their Nature and Mode of Origin. Delivered at University College, October 2, by H. Charlton Bastian, M.A.

This double mode of causation is perfectly familiar to the chemist Particular chemical changes may occur under the influence of certain general determining conditions, which at other times (ir the absence of these conditions) may be even more easily initiated by a single specific cause. The introduction of a crystalline fragment into a saline solution, and its determi nation of the crystallisation of all the isomorphous salts contained in the solution, seems to be exactly comparable with the "contagious" origin of diseases. But, under the influence of certain favourng conditions, crystallisation may occur without the contact of a crystalline fragment--the process may be "spontaneous" in the same sense that the occurrence of the bloodchange may be "spontaneous."

\# Sir H. Holland's "Medical Notes and Reflections," and edition, i840, p. 584. On the following page, the same author writes:- "Connected with these facts is the observation, seemingly well attested, that the choleta some times spreads in face of a prevailing wind, and where no obvious human communication is present-a circumstance difficult, if indeed possible, to be explained, without recourse to animal life as the cause of the phenomenon No mere inorganic matter could be so transferred, nor is vegetable life better provided with means for overcoming this obstacle," Whilst on the preceding page, the "animal species" had been admitted to be "minute, beyond the 
analogies were seemingly strengthened by the increased knowledge which gradually arose concerning the various parasitic maladies to which man and the lower animals were liable. Writing in 1839, Sir Henry Holland says in his essay "On the Hypothesis of Insect-life as a Cause of Disease," "The question is, what weight we may attach to the opinion that certain diseases, and especially some of epidemic and contagious kind, are derived from minute forms of animal life existing in the atmosphere under particular circumstances, and capable, by application to the lining membranes or other parts, of acting as a virts on the human body." Now, the fact of the multiplication of the virus within the body was the peculiarity of these diseases, which, above all others, caused such an hypothesis to be received with favour. Causes which are specific, and which seem capable of self-multiplication-what can such agents be but living things of some kind, plant or animal ? This mode of argument was with many all-powerful. And when, after the discovery of the yeastplant by Schwann, in 1836 , new doctrines concerning fermenta. tion began to prevail, the views of those who believed in the living nature of the specific causes of epidemic diseases were in part strengthened. If all fermentations were initiated by the agency of living organisms, and the specific diseases were comparable to processes of fermentation, then how natural was it that many who were moreover infuenced by the other analogies, should be led to imagine that the specific causes of these diseases were also living organisms. Only now, attention became directed to the much lower organisms which are so 'frequently as. sociated with fermentative and putrefactive changes, instead of to insects " minute beyond the reach of all sense."

Here, then, is the origin of what in modern times has been termed "The Germ-Theory of Disease." Like homœopathy and plirenology, this theory carried with it a kind of simplicity and attractiveness, which insured its acceptability to the minds of many. But, however, it seems to rest upon foundations only a little more worthy of consideration than those upon which these other theories are based. Now, owing to its influence, in combination with the more generally received doctrines concerning the origin of life, there has gradually grown up an unwillingness in the minds of many to believe that these contagious diseases can arise de novo. And this being one of those theories which tends to curb inquiry, and to check the possible growth of sanitary knowledge in certain highly important directions, it seems to me necessary to look with scrutinising care to its foundations, not only with the view to the advancement of medical science, but with the direct object of removing all checks which may exist to the growth of sanitary precautions against the origin of these most pestilential affections.

Let us see, then, how far the "theory" fulfils the conditions which all good theories do fulfil-how far it explains a great number of the phenomena in question, without being irreconcilable with others.

The advocates of the "germ-theory" have always rested their belief in it, in the main; because they considered that it offered a ready explanation of the increase of the virus of the contagious diseases within the body of the affected person. This increase they suppose is not otherwise to be explained. All other considerations brought forward in support of the theory are just as explicable by another supposition. Fully admitting that the occurrence of a process of organic self-reproduction would be a very adequate way of accounting for the increase of the infecting material, we must see whether this mere hypothesis can be reconciled with other characteristics of these affections. In the first place, it may be asked, whether such a process is actually known to constitute the essence of any general diseases. Because, if so, those in which it does occur, ought, in the event of the hypothesis being true, to present a close similarity to the diseases in which such a process is supposed to occur.

Now, there are certain general diseases which do undoubtedly depend upon the presence and multiplication of organisms in the blood and throughout the tissues generally. There is the epidemic and highly contagious distemper amongst cattle, known in this country by the name of the "blood," and which excites in man that most dangerous morbid condition called "malignant pustule:" The researches of M. Davaine " and others have revealed the fact that this disease is essentially dependent upon the presence and multiplication of living organisms, closely allied to Vibriones, in the blood of the animals affected, and that similar organisms are also locally most abundant in the contagiously incited " "malignant pustule" of man. Unless this latter is

* See Comp Rent $186_{4}$ and $186_{5}$ destroyed in its early stages, the contained organisms spread throughout the body and the disease speedily proves fatal. Of late, moreover, attention has also been called * to Pasteur's researches on the subject of the very fatal epidemic which raged for fifteen years amongst the silkworms of France. This affection, known by the name of pebrine, is dependent upon the presence and multiplication of peculiar corpuscular organisms, called Psorospermite, in all the tissues of the body. Both these general parasitic diseases are highly contagious; both are contagious by means of organisms; and in both the virus does increase by self-multiplication within the body of the animal affected. What more suggestive evidence could there be as to the truth of the "germ-theory," say its advocates, than is supplied by the phenomena of these two diseases? Undoubtedly the evidence is irrefragable as to its applicability to these particular maladies; but then comes the question whether they are comparable vith the other affections to which the "germ-theory" is sought to be applied. And this question must decidedly be answered in the negative. These parasitic diseases are sharply distinguished from the others by the fact of their almost invariable fatality. Creatures or persons once affected in this way are, under ordinary circum. stances, thenceforth on the road to more or less immediate death Happily, however, no fatality of this kind is characteristic of even such highly contagious diseases as scarlet fever and smallpox, or any other of the maladies with which parasitic organisms cannot be shown to be associated. Doubtless there are other general parasitic diseases amongst animals. In almost all the specific diseases to which man is liable, however, I have invariably failed to discover any trace of organisms in the blood. The experience of many other observers has been sinilar to my own in this respect. But if living things were really present as causes of these maladies, then most assuredly ought they to conform to that fatal type which is almost inseparable from the notion of a general parasitic disease, and which we find exemplified by the course of pébrine, the "blood," and "malignant pustule." + The fact then, that the general tendency in the acute specific diseases, is undoubtedly towards recovery rather than towards death, speaks strongly against the resemblance supposed to exist between them and the parasitic affections alluded to, and also against the hypothesis that they are dependent upon the presence of self-multiplying germs within the body Such germs, when present, would be sure to go on increasing until they brought about the death of their host.

These considerations alone should suftice to inspire grave doubts as to the truth of the "germ-theory." And such doubts may be reinforced by many others. Thus, the several affections being distinct from one another, this theory demands a belief in the existence of about twenty different kinds of organisms never known in their mature condition, but whose presence as invisible, non-developing germs is constantly postulated, solely on the ground of the occurrence of certain effects supposed to be otherwise incapable of occurring. That, if existent, they are no mere ordinary germs of known organisms is obvious, because the presence of these has again and again been shown to be incapable of producing the diseases in question. Mr. Forster says, "There is not perhaps on the face of the earth a human creature who lives on coarser fare, or to a civilised people more disgusting, than a Kalmuck Tartar. Raw putrid fish or the flesh of carrion-horses, oxen, and camels--is the ordinary food of the Kalmucks, and they are more active and less susceptible to the inclemency of the weather than any race of men I have ever seen." $\$$. It has, moreover, been frequently demonstrated, that the organisms of ordinary putrefactions may be introduced even into the blood of man and animals without the production of any of these specific diseases. II Yet is the "Anticeptic System"

* Nature, 2870, No. ${ }_{3}^{6}$, p. 18 r.

† See paper by Dr. Wm. Budd in British Medical Fourmal, $\times 86_{3}$.

I See Med.-Chirurg. Rev., $x 854$, vol. xiiii, where the supposed connection of diseases with processes of putrefaction is ably considered by the late. $\mathrm{Dr}$. W. Alison.

\$ The Bacteria which are sure to be abundant in such food cannot, therefore, be the much talked-of "disease germs." Such a diet is, of course, by no means recommended. Epidemic diseases are frequently most fatal wher they once break out amongst a people whose diet is of this kind (see Br. Carpenter, in Med. Chirurg. Rev, 1853 , vol. xi. p. x73, and could probably
only be borne in certain climates by persons who lead a very active life. II See, amongst others, Davaine in Compt. Rend, August 1864 , and Nee, amongst others, Davaine in Compt. Rend, August 1864 , and $\mathrm{E}$.
Semmer in Virchow's Archives, 1870. Dr. Lionel 'Beale is well aware of this fact, and he, accordingly, whilst adhering to the germ theory, promul gates it under a new form. He says (Monthly Micros. Four., Oct. 187o p. 205):- "Concerning the conditions under which these germs are produced, and of the manner in which the rapide multiplying matter acquires
ts new and marvellous specific powers, we have much to learn, but with 
of treatment (yood as it may be, irrespective of the germtheory on which it has been based) pressed tupon our attention on the assumption that the germs of putrefaction and the germs of disease are living organisms similar in nature. The strange persistency with which this view is advocated is not a little surprising, when it entails the obvious contradiction that germs which do, under all ordinary circumstances, develop into well-known organic forms, should, when concerned in the production of the diseases in question, induce all the effects supposed to depend upon their prodigious growth and multiplication, and yet never develop, never become visible. And, whilst Bacteria and other organisms with which the unknown disease-germs are compared, flourish and reproduce in the much-vaunted, germ-killing, carbolised lotions;" still carbolic acid continues to be recommended solely on account of its germ-killing powers, and the theory on which the practice is based is thought to derive support from the results obtained by the use of this agent. Surely no theory could be weaker on which to base a successful method of treatment; and if, as its distinguished originator says, $t$ its general acceptance is principally hindered by the "doubt of its fundamental principle," then I would deliberately say that the blame, if any, cannot fairly be said to lie with those "who have opposed the germtheory of putrefaction." The "Antiseptic System" of treatment needs no support from a germ-theory ; it can be surely and unassailably based upon the broader physico-chemicaldoctrines of Liebig.:

The last blow, however, seems given to the "germ-theory" of disease, when we are told that the blood and the secretions in sheep-pox are not infective, though this disease is most closely allied to, and even more yirulently contagious than, human small-pox. If germs had existed in thes general disease, and their multiplication was the cause of it, then most assuredly would they have existed in the blood and in other fluids of the body ; and yet, as Prof. Burdon Sanderson tells us, § "In sheep-pox all the diseased parts are infecting, while no result follows from the inoculation either of the blood or of any of the secretions; the liquid expressed from the pulmonary nodules has been found by M. Chauveau to be extremely virulent---certainly not less so than the juice obtained from the pustules." Now, although in other of these diseases the blood does undoubtedly exhitit infective properties, still the ascertained existence of even one exceptional case amongst maladies so contagious as sheep-pox, seems to be absolutely irreconcilable with the theory of the "germ-theory," more especially when this theory. was started principally to explain the phenomena of such highly contagious diseases.

vegetable organisms the germs have nothing to do. They have originated in man's organism. Man himself has imposed the conditions favourable to in man's organism. Man himself has imposed the conditions favourable to their development. Man alone is responsible for their origin. Human intel-
ligence, energy, and self-sacrifice may succeed in extirpating them, and may discover the means of preventing the origin of new forms not now in exisdiscover the means of preventing the origin of new forms not now in exisence." This is undoubtedly a very much less objectionable form of the germ theory, though much additional evidence would be needed before wc
could accept the view that contagious diseases are due to the rapid multiplicould accept the view that contagious diseases are dire to the rapid multipli-
cation of the contagious particles within the body of the creature affected. cation of the contagious particles within the body of the creature affected.
The non-contagiousness of the blood is as irreconcilable with this as with the other form of the germ theory.

* See "Modes of Origin of Lowest Organisus, 187I, p. 85. And in a * See "Modes of Origin of Lowest Organisus, 187 , P. 85. And in a
recently published paper "On the Relative Powers of Various Substances in Preventing the Generation of Animalcules on the Development of the Germs," Dr. Dougall says: "If, as is alleged, germs are the source of putrefaction, then the strongest preventives must be the best antiseptics, and vice versa. Now, as seen in the table, carbolic acid occupies a very mediocr place as a preventive, therefore it is legitimate to conclude that it stands no higher as an antiseptic," p. $x_{3}$.

+ British Medical fournal, August 26, 187x, p. 225

These doctrines do not seem to have been adequately grasped by Prof. Lister. Fragments of organic matter are believed by Liebig to be capable of acting as ferments; he, however, holds that their potency is deteriorated by heat almost as much as are the qualities of living ferments. The experiments with boiled fluids in bent-neck flasks, therefore, upon which Prof. Lister so strongly relies in proof of the germ-theory, prove absolutely nothing as between the two theories of fermentation of Liebig and of Pasteur. Amongst the atmospheric particles there are sure to be dead ferments in the form of mere organic fragments. Now the doubt that previously existed was, as to whether they could initiate fermentation and putrefaction, or whether the presence of living germs was absolutely essential. In the experiments with bent-neck flasks, both fragments and germs must be simultaneously excluded or admitted to the fluids. Prof. Lister's readers might suppose that Liebig had no objection to his ferments being boiled, and that the issue lay between the relative efficiency of oxygen and living germs. (See Gerhardt's Chimie Organique, t. iv. p. 545.)

\$ Report "On the Intimate Pathology of "Contagion," in Twelfth Report of Medical Officer of Privy Council.

-II Inoculation with the blood of a person suttering from measles has also in several cases failed to reproduce the disease. The different severity of small-pox taken in the ordinary way, and that induced by "inoculation" of the matter of a small-pox pustule, is also quite inexplicable in ar.cordance
with the "germ theory."
Dr. Bastian tabulates the whole of the communicable diseases in the following manner :-

$$
\begin{aligned}
& \text { Paradtic Diseases affecting: }
\end{aligned}
$$

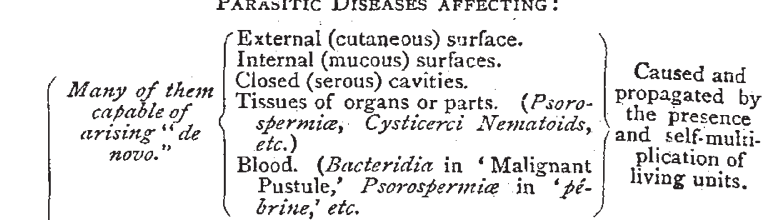

Tissue Diseases.

A. Diseases of Internal Formed Tissues

and of Mucous Membranes.

Fibro-plastic growths.

All inoculable $\begin{aligned} & \text { Cancerous growths. } \\ & \text { Tubercular growths }\end{aligned}$

and capable of Glanders.

arising "de Syphilis.

novo." Ge Gonorrhœa.

Purulent ophtnalmia.

Diphtheria and Croup Principally

B. Diseases of the Blood (principally).

All contagious ( Erysipelas.

and capable of Surgical fever.

arising".de Pyæmia.

Hospital gangrene.
Rabies.

Rheuriatic fever

a. Dengue.

b. Sweating sickness

Intermitten: fever.

a. Remittent fever
b. Yellow fever.

b. Yellow fever.
Summer diarrhcea.

Summer diarrhoea.

Contagionsiness

either absent,

little marked,

or nitore or less

probably

capable of

mowo."

Dysentery.

Influenza.

Mumps.

Relapsing fever.

Typhoid fever.

Typhus fever.

$\left\{\begin{array}{c}\text { Oftent } \\ \text { Epident }\end{array}\right.$

menningitis?

b. Plague.

Varicella.

Hooping cough.

Measles.

Scarlet fever.

Small-pox.

Sparadic.

\section{BOOKS RECEIVED}

ENGLISH.-The Subterranean World: Dr. G. Hartwig (Longmans and Co.).-Or. the Use of the Ophthalmoscope: T. C. Allbut (Macmillan and Co.)-Rudimentary Treatise on Geology ; Part I., Physical : Ralph Tait (Lockwood and Co.).

\section{CONTENTS}

PAGE

Observations upon Magnetic Storms in Higher Latitudei . 44 The Light of Jupiter's Satellite9. By Rev. T. W. WebB,

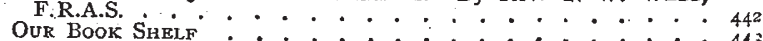
LUR BOOK SHELF TO THE EDITOR:

On the Solution of I Certain Geometrical Prublem.-I. Todhunter 44 Stricturetof Fossil'Cryptogams - Prof.W. THISELToN DYer, F.L.S. 444 The Solar specurum. - Prof. C. A. Young . Eclipse Photography and the spectroscope.-Henry DAvis $\dot{D}^{\circ} \cdot 445$ Phenomena of Contact. - R. A. Proctor, F.R.A.S.

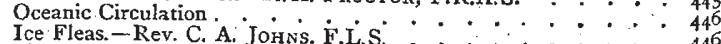
Tce Fleas. - Rev. C. A. Johns, F.L.S. . . . . . . . . . : 446

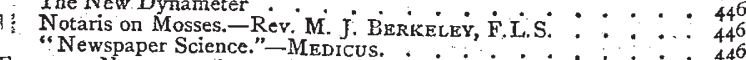

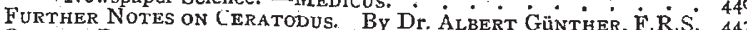
ON THE BENDING OF GLACIER ICE By Prof J TYNDALR F. 447 THE MigRation of QUAIL. . . . . . . . . . . . . 447 JARDIN D'ESSA, ALGER Q THE TEMPERATLRE OF THE SUN. By J. ERICSSON $: *:{ }_{4} 44$ Notes - . * : : : $4_{452}^{4}$ ON THE STUDY OF ScIENCE IN SChOOLS.-No.il. By G. F. Rod 45 WELL, F.C.S. $\because \cdot 455$ YACHT " NORNA" OFF THE COAST OF SPAIN EXPEDITION OF THE W. Saylle Kent, F.Z S. Prof. Bastian on The Germ-Theory: : : : : : : : : $45^{8}$

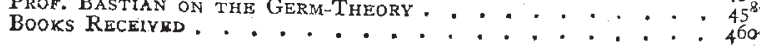

